EL MUHASABA: Jurnal Akuntansi (e-Journal)

Volume 12 , No. 1, Tahun 2021

P ISSN: 2086-1249 ; E ISSN: 2442-8922

\title{
OPINI AUDIT, AUDIT REPORT LAG, REPORTING DELAY, KAP, DAN EPS SEBAGAI DETERMINAN HARGA SAHAM
}

\author{
Santika Maya Rindika1, Nina Dwi Setyaningsih ${ }^{2}$ \\ Universitas Islam Negeri Maulana Malik Ibrahim Malang1,2 \\ Jl. Gajayana No. 50 Malang, 65144, Indonesia \\ e-mail:santikamaya3@gmail.com ${ }^{1}$
}

\section{Abstract}

The information about company's financial performance can be obtained by investor in company's financial report. Some of the informations are audit opinion, audit report lag, reporting delay, KAP, and EPS. That informations are used by investor to do an investment analysis through financial report that can influence investment decision. Investor's investment decision can influence stock price change. The purposes of this research are to determine the simultan and partial effect of audit opinion, audit report lag, reporting delay, KAP, and EPS on stock price. Research type that is used quantitative method and descriptive approach. Research data are financial reports and stock prices with banking companies listed on Indonesia Stock Exchange (BEI) within year of 2016-2018 as a population. Purposive sampling is used as a sampling method so obtained 23 samples. The research method is using multiple linier regression analysis. The results of this research are simultaneously audit opinion, audit report lag, reporting delay, KAP, and EPS have significant influence to stock prices. Partially, reporting delay and EPS have significant positive influence to stock prices. Meanwhile, audit opinion, audit report lag, and KAP have no effect on stock prices.

Keywords : Audit Opinion, Audit Report Lag, Reporting Delay, KAP, EPS, and Stock Price.

\section{Abstrak}

Tujuan penelitian ini untuk mengidentifikasi pengaruh parsial dan simultan dari opini audit, audit report lag, reporting delay, KAP, dan EPS terhadap harga saham. Jenis penelitian kuantitatif dan pendekatan deskriptif, dianalisis menggunakan regresi linier berganda. Hasil atas penelitian menunjukkan bahwa secara simultan opini audit, audit report lag, reporting delay, KAP dan EPS berpengaruh signifikan terhadap harga saham. Secara parsial harga saham secara signifikan positif dipengaruhi oleh Reporting delay dan EPS, tetapi harga saham tidak dipengaruhi oleh opini audit, audit report lag, dan KAP.

Kata Kunci : Opini Audit, Audit Report Lag, Reporting Delay, KAP, EPS, dan Harga Saham

\section{PENDAHULUAN}

OJK dapat menerima laporan keuangan maksimal di akhir bulan April setelah tutup buku. Laporan kwuangan yang akan diserahkan kepada OJK harus 
Santika Maya Rindika, Nina Dwi Setyaningsih : Opini Audit, Audit Report Lag, Reporting Delay, Kap, Dan Eps Sebagai Determinan Harga Saham

telah diaudit yang dijelaskan pada BAB I Pasal 4 huruf (i). Hal tersebut tertera di POJK No. 29/POJK.04/2016.

Audit mengakibatkan timbulnya opini audit. Pengambilan keputusan investor atas investasinya dipengaruhi oleh opini audit karena opini audit menjadi refleksi atas seberapa wajar kandungn dalam laporan keuangan (Pardosi, 2012). Penelitian Chandra dan Arisman (2016) menghasilkan kesimupulan opini audit pada laporan keuangan memberikan detreminasi kepada harga saham. Hasil tersebut berbanding lurus dengan milik Sidabutar (2014). Namun penelitian Nugrahani dan Ruhiyat (2018) menyatakan harga saham tidak dideterminasi opini audit, hasil tersebut sejalan oleh penelitian milik Pardosi (2012), Marindah (2013), dan Susila (2015).

Jangka waktu dibutuhkan dalam proses perolehan opini audit yang dikenal dengan audit report lag. Pardosi (2012) menyatakan bahwa harga saham tidak dipengaruhi oleh audit report lag, berbanding lurus dengan pendapat Marindah (2013). Sedangkan, penelitian milik Sidabutar (2014) membuktikan adanya pengaruh secara negatif dari audit report lag kepada harga saham.

Panjang dari audit report lag dapat menjadi dampak dari waktu pempublikasian laporan keuangan dikarenakan publikasi bisa dilakukan jika audit telah selesai dilaksanakan. Penelitian oleh Martinus (2017) menyimpulkan tidak terdapat determinasi reporting delay akan harga saham, sejalan dengan hasil penelitian oleh Sutrisna, Purnamawati, dan Wahyuni (2017). Namun, penelitian oleh Salehan (2016) menghasilkan kesimpulan yang sebaliknya.

Reporting delay yang diakibatkan opini audit dan audit report lag menjadi tanggung jawab auditor. Kantor akuntan public (KAP) dengan peringkat tinggi telah dianggap mempunyai keahlian yang baik dalam melakukan pendeteksian salah saji atas laporan keuangan (Almuntaha dkk, 2016). Pardosi (2012) dalam penelitiannya menyatakan harga saham dipengaruhi KAP, berbanding lurus dengan hasil penelitian Sidabutar (2014) dan Chandra dan Arsiman (2016). Namun hasil penelitian oleh Marindah (2013) memberikan hasil jika harga saham tidak dipengaruhi KAP.

Infomasi lain dalam laporan keuangan salah satunya yakni Earning Per Share atau EPS menjadi informasi yang mengindikasikan tingkat sejahtera perusahaan, artinya jika niai EPS cukup tinggi maka menjadi indikasi perusahaan dapat mensejahterakan investor dengan baik. Marcellyna dan Hartini (2013) mengungkapkan bahwa harga saham dipengaruhi EPS, berbanding lurus dengan pendapat Marindah (2013). Tetapi, Yolanda (2017) menyatakan jika tidak adanya pengaruh EPS pengaruh terhadap harga saham.

Sektor perbankan menjadi objek dalam penelitian ini dengan memoertimbangkan saran oleh Nugrahani dan Ruhiyat (2018) untuk dilakukan penelitian pada sektor selain manufaktur. Sebelum penelitian ini terlaksana, telah dilaksanakan penelitian-penelitian yang menjadikan variabel-variabel independen tersebut untuk melihat determinasinya kepada variabel dependen 
Santika Maya Rindika, Nina Dwi Setyaningsih : Opini Audit, Audit Report Lag, Reporting Delay, Kap, Dan Eps Sebagai Determinan Harga Saham

yakni harga saham, namun menghasilkan kesimpulan yang tidak konsisten. Variabel independen pada penelitian ini menjadi pembeda dengan penelitianpenelitian yang ada, yakni dilakukannya pengembangan dengan menggabungkan beberapa variabel independen pada penelitian-penelitian yang ada.

\section{KAJIAN PUSTAKA}

\section{Laporan Keuangan}

Laporan keuangan didefinisikan oleh PSAK No. 1 (IAI, 2014) sebagai penyajian atas posisi dan kinerja keuangan perusahaan secara terstruktur. Laporan keuangan disajikan secara utuh jika terdapat: 1) laporan atas posisi keuangan, 2) laporan atas laba rugi, 3) laporan atas perubahan ekuitas, dan 4) CALK (Catatan Atas Laporan Keuangan).

\section{Auditing}

Rick Hayes (2017) mendefinisikan audit sebagai pendekatan sistematis. Audit menggunakan perencanaan terstruktur dan dokumentasikan. Pada proses pengauditan, dilakukan analisis atas catatan dari akuntansi menggunakan teknik umum yang digunakan oleh auditor.

\section{Opini Audit}

Wiranti (2012) mendefinisikan opini audit sebagai pendapat auditor atas hasil audit yang telah selesai dan dikeluarkan melalui pertimbangan secara profesional dan diatur dalam SPAP.

\section{Audit Report Lag}

Audit repot lag diartikan sebagai lama dari hari yang dibutuhkan dalam proses dihitung pada jumlah hari antara tanggal laporan audit dengan tanggal penutupan buku perusahaan yakni setiap akhir Desember (Rahmawati, 2011).

\section{Kantor Akuntan Publik (KAP)}

KAP merupakan entitas jasa tentang audit kepatuhan, operasional, maupun laporan keuangan (Arens \& Loebbecke, 2009). KAP big four menurut Rimdani (2018) terdiri dari empat KAP, yakni KAP Deloitte Tauche Thomatsu, KAP Pricewaterhouse Coopers, KAP Ernst and Young, dan KAP KPMG.

\section{Reporting Delay}

Cullinan et al. (2012) mendefinisikan reporting delay sebagai waktu yang lebih Panjang dalam proses penerbitan laporan keuangan oleh perusahaan dari periode yang sebelumnya. Peraturan tentang laporan keuangan perusahaan terdapat pada POJK nomor 29/POJK.04/2016, yang berisi tentang pernyataan kewajiban perusahaan agar menyetorkan laporan paling lambat pada berakhirnya bulan April kepada OJK.

\section{Earning Per Share (EPS)}

EPS menjadi informasi yang bisa dimanfaatkan dalam melakukan prediksi return saham berbentuk rasio keuangan, rasio tersebut dapat dimanfaatkan oleh investor sebagai nformasi jangka pendek (Samsul, 2006). 
Santika Maya Rindika, Nina Dwi Setyaningsih : Opini Audit, Audit Report Lag, Reporting Delay, Kap, Dan Eps Sebagai Determinan Harga Saham

\section{Saham}

Irham (2014) mendefinisikan saham sebagai bukti atas penanaman modal atas suatu entitas.

\section{Harga Saham}

Harga saham adalah harga yang perlu dibayar untuk memiliki per lembar suatu saham. Interaksi pembeli dan penjual menjadi dasar terbentuknya harga saham (Laksitafresti, 2012).

\section{Teori Sinyal}

Teori sinyal mengartikan jika pejabat tertinggi dari suatu institusi mempunyai lebih banyak informasi dan akan mempublikasi nformasi- informasi tersebut untuk pihak external dengan tujuan meningkatkan harga saham (Dwiyanti, 2010).

\section{Efisiensi Pasar}

Hartono (2014) menyatakan bahwa apabila harga keseimbagan baru dapat dicapai oleh suatu pasar dengan cepat dan akurat dinyatakan sebagai pasar efisien. Bagaimana pasar dalam mengolah informasi pada ekuilibrium baru menjadi konsep pasar efisien.

\section{HIPOTESIS}

\section{Pengaruh Opini Audit Terhadap Harga Saham}

Penelitian Chandra dan Arisman (2016) menghasilkan kesimupulan opini audit pada laporan keuangan memberikan detreminasi kepada harga saham. Hasil tersebut berbanding lurus dengan milik Sidabutar (2014). Namun penelitian Nugrahani dan Ruhiyat (2018) menyatakan harga saham tidak dideterminasi opini audit, hasil tersebut sejalan oleh penelitian milik Pardosi (2012), Marindah (2013), dan Susila (2015).

H1 : Harga Saham dipengaruhi Opini Audit.

\section{Pengaruh Audit Report Lag terhadap Harga Saham}

Pardosi (2012) menyatakan bahwa harga saham tidak dipengaruhi oleh audit report lag, berbanding lurus dengan pendapat Marindah (2013). Sedangkan, penelitian milik Sidabutar (2014) membuktikan adanya pengaruh secara negatif dari audit report lag kepada harga saham.

H2 : Harga Saham dipengaruhi Audit Report Lag.

\section{Pengaruh Reporting Delay terhadap Harga Saham}

Martinus (2017) menunjukkan bahwa tidak terdapat determinasi keterlambatan pelaporan keuangan (reporting delay) akan harga saham, sejalan dengan hasil penelitian oleh Sutrisna, Purnamawati, dan Wahyuni (2017). Namun, penelitian oleh Salehan (2016) menghasilkan kesimpulan yang sebaliknya.

H3 : Harga Saham dipengaruhi Reporting Delay.

Pengaruh Kantor Akuntan Publik (KAP) terhadap Harga Saham

Pardosi (2012) dalam penelitiannya menyatakan harga saham dipengaruhi 
Santika Maya Rindika, Nina Dwi Setyaningsih : Opini Audit, Audit Report Lag, Reporting Delay, Kap, Dan Eps Sebagai Determinan Harga Saham

KAP, berbanding lurus dengan hasil penelitian Sidabutar (2014) dan Chandra dan Arsiman (2016). Namun hasil penelitian oleh Marindah (2013) memberikan hasil jika harga saham tidak dipengaruhi KAP.H4 : Harga Saham dipengaruhi Kantor Akuntan Publik (KAP).

H4 : Harga Saham dipengaruhi KAP.

\section{Pengaruh Earning Per Share (EPS) terhadap Harga Saham}

Marcellyna dan Hartini (2013) mengungkapkan bahwa harga saham dipengaruhi EPS, berbanding lurus dengan pendapat Marindah (2013). Tetapi, Yolanda (2017) menyatakan jika tidak adanya pengaruh EPS pengaruh terhadap harga saham.

H5 : Harga Saham dipengaruhi Earning Per Share (EPS).

\section{METODE}

Penelitian kuantitatif melalui pendekatan penelitian deskriptif menjadi metode penelitian yang diterapkan.

\section{Populasi dan Sampel}

Perusahaan perbankan pada Bursa Efek ndonesia (BEI) tahun 2016-2018 merupakan populasi penelitian. Sedangkan sampel atas populasi dipilih dengan kriteria-kriteria sebagai brikut:

1. Terdaftar pada Bursa Efek Indonesia (BEI) tahun 2016-2019.

2. Melakukan publikasi laporan keuangan di Bursa Efek Indoensia (BEI) tahun 2016-2018.

3. Melampirkan laporan audit pada laporan keuangan tahun 2016-2018.

4. Tidak mengalami kerugian pada tahun 2016-2018.

\section{Teknik Pengambilan Sampel}

Purposive sampling merupakan salah satu teknik dalam mengambil sampel dimana sampel diambil berasarkan kualifikasi tertentu agar data yang didapat sesuai dengan kebutuhan penelitian (Sugiyono, 2010). Sehingga dari 44 populasi didapatkan 23 perusahaan yang menghasilkan 69 sampel.

\section{Data dan Jenis Data}

Laporan keuangan, laporan audit, waktu pelaporan keuangan, dan harga saham merupakan jenis data sekunder yang digunakan untuk penelitian. Data tersebut diperoleh dari web BEI.

\section{Teknik Pengumpulan Data}

Data didapatkan dalam laporan keuangan, laporan audit, waktu pelaporan keuangan, dan harga saham. Data-data tersebut didapatkan melalui web Bursa Efek ndonesia (BEI) dan alat untuk mengolah data menggunakan software SPSS versi 26 untuk statistik.

\section{Analisis Data}

Ln (Logaritma Natural) digunakan dalam penelitian ini karena skala yang digunakan berupa skala nominal dan skala dummy, sehingga data harus ditansformasi dengan skala nominal menggunakan Ln agar didapat data yang 
Santika Maya Rindika, Nina Dwi Setyaningsih : Opini Audit, Audit Report Lag, Reporting Delay, Kap, Dan Eps Sebagai Determinan Harga Saham

normal dan memenuhi ketentuan regresi linier berganda (Chandra dan Arisman, 2016).

HASIL DAN PEMBAHASAN

Tabel 1. Tabel Statistik Deskriptif Descriptive Statistics

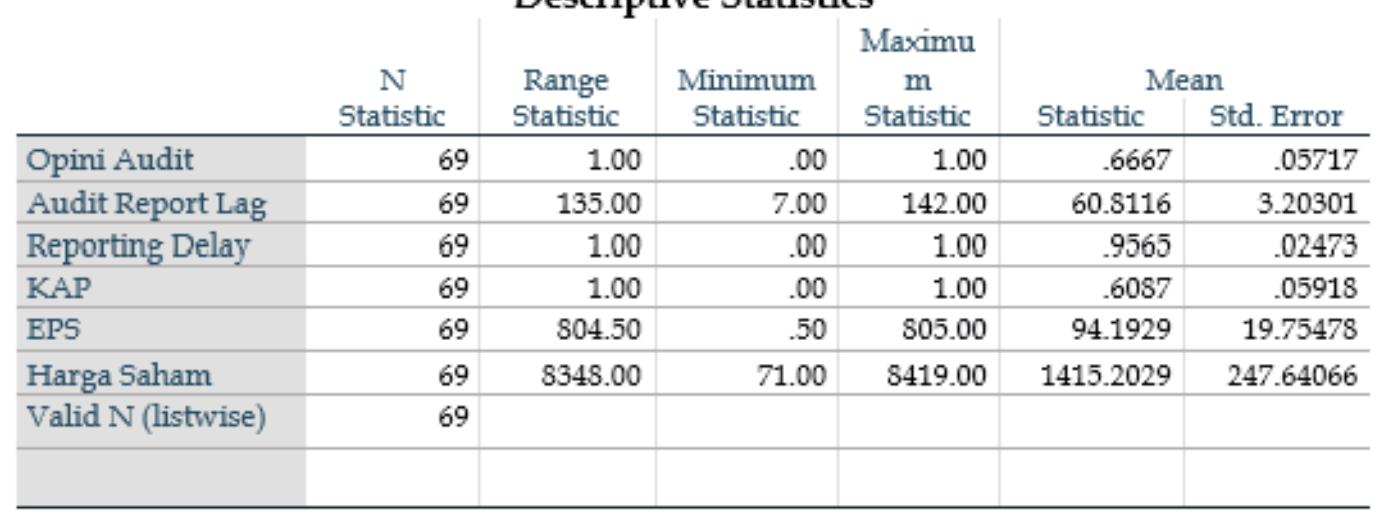

\section{Sumber: Hasil Analisis (2020)}

\section{Uji Asumsi Klasik}

\section{Uji Normalitas}

Uji normalitas merupakan pengujian agar data memiliki distribusi yang normal melalui alat uji one sample Kolmogorov- Smirnow (Ghozali, 2007).

Tabel 2. Tabel Uji Normalitas One-Sample Kolmogorov-Smirnov Test

\begin{tabular}{llr} 
& & $\begin{array}{c}\text { Unstandardized } \\
\text { Residual }\end{array}$ \\
\hline $\mathrm{N}$ & Mean & 69 \\
\cline { 2 - 3 } Normal Parametersab & Std. Deviation & .0000000 \\
\hline Most Extreme Differences & Absolute & .67006616 \\
\cline { 2 - 3 } & Positive & .083 \\
\hline Test Statistic & & .083 \\
\hline Asymp. Sig. (2-tailed) & & .083 \\
\hline
\end{tabular}

Sumber: Hasil Analisis (2020)

Berdasarkan hasil diatas nilai signifikansi adalah 0,200, maka data dinyatakan berdistribusi normal dikarenakan nilai significance melebihi 0,05 $(0,200>0,05)$.

\section{Uji Multikolinearitas}

Uji muktikolinearitas merupakan suatu uji untuk mengetahui terdapat atau tidak hubungan antar variabel independen (Ghozali, 2007). 
Santika Maya Rindika, Nina Dwi Setyaningsih : Opini Audit, Audit Report Lag, Reporting Delay, Kap, Dan Eps Sebagai Determinan Harga Saham

\begin{tabular}{|c|c|c|c|c|c|c|c|c|}
\hline \multicolumn{9}{|c|}{$\begin{array}{c}\text { Tabel 3. Tabel Uji Multikolinearitas } \\
\text { Coefficients }{ }^{a}\end{array}$} \\
\hline \multirow{2}{*}{\multicolumn{2}{|c|}{ Model }} & \multicolumn{2}{|c|}{$\begin{array}{l}\text { Unstandardized } \\
\text { Coefficients }\end{array}$} & \multirow{2}{*}{$\begin{array}{l}\text { Standardiz } \\
\text { ed } \\
\text { Coefficients } \\
\text { Beta } \\
\end{array}$} & \multirow[b]{2}{*}{$t$} & \multirow[b]{2}{*}{ Sig. } & \multicolumn{2}{|c|}{$\begin{array}{l}\text { Collinearity } \\
\text { Statistics }\end{array}$} \\
\hline & & B & Std. Error & & & & $\mathrm{e}$ & VIF \\
\hline 1 & (Constant) & 2.905 & 1.048 & & 2.772 & .007 & & \\
\hline & Opini Audit & .256 & .195 & .096 & 1.318 & .192 & .834 & 1.198 \\
\hline & Ln_ARL & .103 & .185 & .047 & .558 & .579 & .620 & 1.614 \\
\hline & $\begin{array}{l}\text { Reporting } \\
\text { Delay }\end{array}$ & .897 & .430 & .145 & 2.088 & .041 & .915 & 1.093 \\
\hline & KAP & -.044 & .190 & -.017 & -.232 & .818 & .820 & 1.220 \\
\hline & Ln_EPS & .650 & .066 & .868 & 9.866 & .000 & .570 & 1.753 \\
\hline
\end{tabular}

\section{Sumber: Hasil Analisis (2020)}

Multikolinieritas tidak terjadi berdasarkan tabel diatas. Hal ini dapat dilihat pada kolom tolerance nilai untuk variabel opini audit, audit report lag, reporting delay, KAP, dan EPS melebihi 0,10. Pada kolom VIF nilai variabel opini audit, audit report lag, reporting delay, KAP, dan EPS dibawah 10.

\section{Uji Autokorelasi}

Uji autokorelasi memiliki tujuan mendeteksi terdapat atau tidak hubungan dari kesalahan pengganggu yang terjadi pada periode $t$ dengan periode yang sebelumnya (Ghozali, 2007). Santoso (2005) dalam Oktaviani (2016) menyatakan apabila nilai atas DW lebih besar dai -2 tetapi dibawah 2 dinyatakan tidak terdeteksi autokorelasi.

\section{Tabel 4. Tabel Uji Autokorelasi}

\begin{tabular}{|c|c|c|c|c|c|}
\hline \multicolumn{6}{|c|}{ Model Summaryb } \\
\hline Model & $\mathrm{R}$ & R Square & $\begin{array}{l}\text { Adjusted R } \\
\text { Square }\end{array}$ & $\begin{array}{l}\text { Std. Error of the } \\
\text { Estimate }\end{array}$ & Durbin-Watson \\
\hline 1 & $.850^{2}$ & .722 & .700 & .69615 & .981 \\
\hline
\end{tabular}

\section{Sumber: Hasil Analisis (2020)}

Hasil diatas menunjukkan nilai DW adalah sebesar 0,981. Nilai tersebut mrngimplikasikan bahwa tidak terdapat masalah pada autokorelasi karena DW berada pada posisi diantara -2 dan $2(-2<0,981<2)$.

\section{Uji Heteroskedastisitas}

Uji heteroskedastisitas merupakan uji atas terdapat atau tidak terdapat perbedaan atas variance dari residual antar pengamatan (Ghozali, 2007).

Hasil yang ada pada tabel 5 menunjukkan nilai dari significance variabel opini audit, audit report lag, reporting delay, KAP, dan EPS melebihi 0,05, maka kesimpulannya heteroskedastisitas tidak terdeteksi. 
Santika Maya Rindika, Nina Dwi Setyaningsih : Opini Audit, Audit Report Lag, Reporting Delay, Kap, Dan Eps Sebagai Determinan Harga Saham

\begin{tabular}{|c|c|c|c|c|c|c|}
\hline \multicolumn{7}{|c|}{ Tabel 5. Tabel Uji Heteroskedastisitas } \\
\hline \multicolumn{7}{|c|}{ Coefficients ${ }^{a}$} \\
\hline \multirow[b]{2}{*}{ Model } & & \multicolumn{2}{|c|}{ Unstandardized Coefficients } & \multirow{2}{*}{$\begin{array}{c}\text { Standardized } \\
\text { Coefficients } \\
\text { Beta }\end{array}$} & \multirow[b]{2}{*}{$t$} & \multirow[b]{2}{*}{ Sig. } \\
\hline & & B & Std. Error & & & \\
\hline 1 & (Constant) & -.099 & .533 & & -.185 & .854 \\
\hline & Opini Audit & .036 & .099 & .048 & .366 & .716 \\
\hline & Ln_ARL & .068 & .094 & .109 & .721 & .473 \\
\hline & Reporting Delay & .427 & .218 & .243 & 1.954 & .055 \\
\hline & KAP & .106 & .096 & .144 & 1.099 & .276 \\
\hline & Ln_EPS & -.033 & .033 & -.156 & -.993 & .324 \\
\hline
\end{tabular}

Sumber: Hasil Analisis (2020)

\section{Uji Hipotesis}

Analisis Regresi Linier Berganda

Analisis regresi linier berganda ialah bentuk perluasan dari regresi linier sederhana yakni terdapat penambahan jumlah variabel independen menjadi lebih dari satu (Sanusi, 2011).

\section{Tabel 6. Tabel Analisis Regresi Linier Berganda} Coefficients ${ }^{2}$

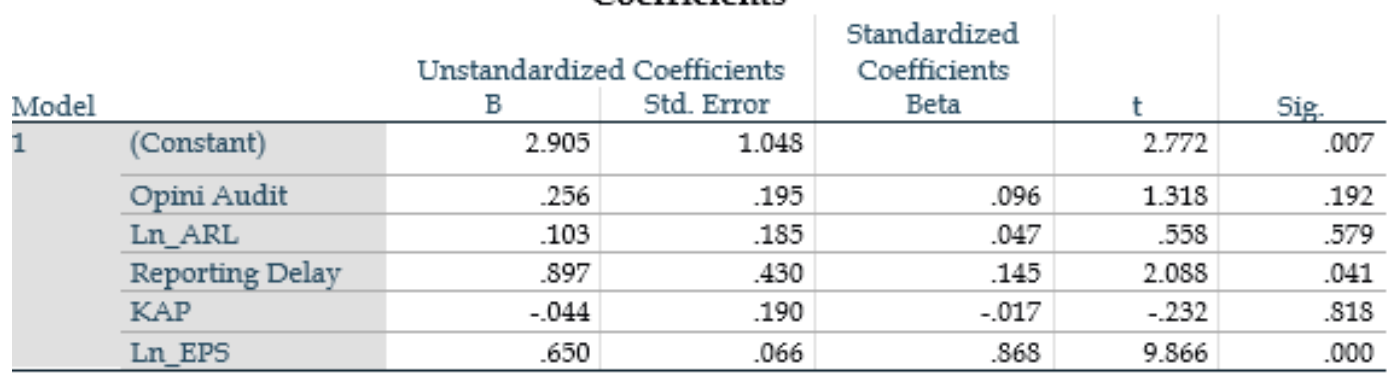

\section{Sumber: Hasil Analisis (2020)}

\section{Uji T (Parsial)}

Uji $\mathrm{T}$ merupakan alat deteksi keberadaan pengaruh parsial variabel independen kepada variabel dependen (Ghozali, 2007). Hasil atas uji $t$ terdapat di tabel coefficients pada kolom $t$ dan significance.

\begin{tabular}{|c|c|c|c|c|c|c|}
\hline \multicolumn{7}{|c|}{$\begin{array}{c}\text { Tabel 7. Tabel Uji T (Parsial) } \\
\text { Coefficients }{ }^{\circledR}\end{array}$} \\
\hline \multirow[b]{2}{*}{ Model } & & \multicolumn{2}{|c|}{ Unstandardized Coefficients } & \multirow{2}{*}{$\begin{array}{c}\text { Standardized } \\
\text { Coefficients } \\
\text { Beta }\end{array}$} & \multirow[b]{2}{*}{$\mathrm{t}$} & \multirow[b]{2}{*}{ Sig. } \\
\hline & & B & Std. Error & & & \\
\hline 1 & (Constant) & 2.905 & 1.048 & & 2.772 & .007 \\
\hline & Opini Audit & .256 & .195 & .096 & 1.318 & .192 \\
\hline & Ln_ARL & .103 & .185 & .047 & .558 & .579 \\
\hline & Reporting Delay & .897 & .430 & .145 & 2.088 & .041 \\
\hline & KAP & -.044 & .190 & -.017 & -.232 & .818 \\
\hline & Ln_EPS & .650 & .066 & .868 & 9.866 & .000 \\
\hline
\end{tabular}

\section{Sumber: Hasil Analisis (2020)}

T hitung variabel opini audit dibawah nilai $t$ tabel $(1,318<1,998)$. Maka harga saham tidak dipengaruhi opini audit. Hasil tersebut memiliki kesamaan dengan hasil penelitian oleh Pardosi (2012), Marindah (2013), Susila (2015), dan Nugrahani dan Ruhiyat (2018). Maka, investor tidak menjadikan opini audit 
Santika Maya Rindika, Nina Dwi Setyaningsih : Opini Audit, Audit Report Lag, Reporting Delay, Kap, Dan Eps Sebagai Determinan Harga Saham

sebagai informasi yang digunakan dalam bertransaksi saham.

Nilai thitung dari variabel audit report lag dibawah nilai $t$ tabel $(0,558<1,998)$. Maka harga saham tidak dipengaruhi audit report lag. Hasil tersebut mendukung hasil penelitian Pardosi (2012) dan Marindah (2013) yang menandakan bahwa investor atau tidak melihat rentang waktu dalam proses audit sebelum melakukan transaksi saham.

Nilai $\mathrm{t}$ hitung dari variabel reporting delay melebihi nilai $\mathrm{t}$ tabel $(2,088>$ 1,998). Maka secara positif signifikan harga saham dipengaruhi oleh reporting delay. Hasil tersebut berbanding lurus dengan hasil Salehan (2016). Hasil penelitian ini menandakan waktu dikeluarkannya laporan keuangan menjadi aspek yang diperhatikan dalam bertransaksi saham.

Nilai $t$ hitung dari variabel KAP dibawah nilai $t$ tabel $(-0,232<1,998)$. Maka harga saham tidak dipengaruhi KAP. Hasil penelitian ini menyetujui hasil penelitian oleh Marindah (2013) yang menandakan bahwa KAP bukan menjadi tolak ukur sebelum melakukan transaksi saham.

Nilai t hitung dari variabel EPS melebihi nilai $t$ tabel $(9,866>1,998)$. Maka secara positif signifikan terdapat pengaruh dari EPS kepada harga saham. Hasil penelitian tersebut sama dengan milik Marindah (2013) dan Marcellyna dan Hartini (2013). Maka, investor menjadikan EPS sebagai sinyal dalam melakukan transaksi.

\section{Uji F (Simultan)}

Uji F merupakan alat deteksi atas pengaruh yang diterima variabel dependen secara bersama-sama dari variabel-variabel independen (Ghozali, 2007). Hasil atas uji F dapat disimpulkan dengan melihat tabel annova pada kolom sig.

Tabel 8. Tabel Uji F (Simultan)

\begin{tabular}{|c|c|c|c|c|c|c|}
\hline \multicolumn{7}{|c|}{ ANOVA } \\
\hline & & Sum of Squares & df & Mean Square & $\mathrm{F}$ & Sig. \\
\hline \multirow[t]{3}{*}{1} & Regression & 79.319 & 5 & 15.864 & 32.734 & $.000^{\mathrm{b}}$ \\
\hline & Residual & 30.531 & 63 & .485 & & \\
\hline & Total & 109.850 & 68 & & & \\
\hline
\end{tabular}

\section{Sumber: Hasil Analisis (2020)}

Nilai f hitung berdasarkan hasil diatas melebihi nilai f tabel $(32,734>2,52)$. Sedangkan nilai signifikansinya lebih kecil dari 0,05 $(0,000<0,05)$. Maka secara bersamaan atau simultan harga saham dipengaruhi oleh variabel opini audit, audit report lag, reporting delay, $\mathrm{KAP}$, dan EPS.

\section{Koefisien Determinasi $\left(R^{2}\right)$}

Koefisien determinasi merupakan ukuran nilai tentang besaran kemampuan menjelaskan dari variabel-variabel independen atas variabel dependen (Ghozali, 2007). 
Santika Maya Rindika, Nina Dwi Setyaningsih : Opini Audit, Audit Report Lag, Reporting Delay, Kap, Dan Eps Sebagai Determinan Harga Saham

Tabel 9. Tabel Koefisein Determinasi

\begin{tabular}{ll|r|r|r} 
& & \multicolumn{2}{c}{ Model Summaryb } \\
Model & $R$ & R Square & $\begin{array}{c}\text { Adjusted R } \\
\text { Square }\end{array}$ & $\begin{array}{c}\text { Std. Error of the } \\
\text { Estimate }\end{array}$ \\
\hline 1 & $.850^{*}$ & .722 & .700 & .69615 \\
\hline
\end{tabular}

\section{Sumber: Hasil Analisis (2020)}

Berdasarkan hasil diatas $\mathrm{R}^{2}$ adalah sebesar 0,722. Hasil tersebut bermakna variabel dependen diterangkan oleh variabel-variabel independen seluas $72,2 \%$. Sedangkan sebesar 27,8\% adalah kemampuan variabel-variabel independen lain diluar penelitian ini untuk menjelaskan variabel dependen.

\section{KESIMPULAN}

Hasil pengujian regresi yang dilakukan pada penelitian ini menunjukkan beberapa hal. Tidak terdeteksi atas pengaruh antara opini audit terhadap harga saham. Harga saham tidak dipengaruhi oleh audit report lag. Harga saham secara signifikan positif dipengaruhi oleh variabel reporting delay. Harga saham tidak dipengaruhi oleh variabel KAP. Harga saham secara signifikan positif dipengaruhi oleh variabel EPS. Harga saham secara simultan dipengaruhi oleh variabel opini audit, audit report lag, reporting delay, KAP, dan EPS.

Saran yang diberikan untuk penelitian selanjutnya yaitu, melakukan penggantian atau penambahan variabel independen. Melakukan penelitian pada sektor industri yang lain.

\section{DAFTAR PUSTAKA}

Almuntaha, Eska dan Angelia Pribadi. 2016. Apakah Reputasi Kantor Akuntan Publik Mempengaruhi Kestabilan Harga Saham ?. Simposium Nasional Akuntansi XIX.

Arens and Loebbecke. 2009. Auditing Pendekatan Terpadu, Edisi Indonesia, (Amir. Abadi Jusuf, Penterjemah). Jakarta: Salemba Empat.

Chandra, Jeffrey, Arisman, Anton. 2016. Pengaruh Opini Audit dan Ukuran Kantor Akuntan Publik Terhadap Harga Saham, http://eprints.mdp.ac.id/1982/, diakses tanggal 25 September 2019.

Cullinan, C. P., Wang, F., Yang, B., \& Zhang, J. 2012. Audit Opinion Improvement and the timing of disclosure. Advances in Accounting. Incorporating Advances International Accounting. Hal. 333-343.

Darmawan, Deni. 2018. Metode Penelitian Kuantitatif. Bandung: PT. Remaja Rosdakarya. 
Santika Maya Rindika, Nina Dwi Setyaningsih : Opini Audit, Audit Report Lag, Reporting Delay, Kap, Dan Eps Sebagai Determinan Harga Saham

Dwiyanti, Rini. 2010. Analisis Faktor-Faktor yang Mempengaruhi Ketepatan Waktu Pelaporan Keuangan Pada Perusahaan Manufaktur yang Terdaftar di Bursa Efek Indonesia. Skripsi. Fakultas Ekonomi Universitas Diponegoro, Semarang.

Ghozali, Imam. 2007. Aplikasi Multivariate dengan Program SPSS. Semarang: UNDIP.

Hartono, Jogiyanto. 2014. Teori Portofolio dan Analisis Investasi Edisi-10. Yogyakarta: BPFE UGM.

Hayes, Rick, Wallage, Philip, \& Gortemaker, Hans. 2017. Prinsip-Prinsip Pengauditan. Jakarta: Salemba Empat.

Ikatan Akuntansi Indonesia. 2014. Standar Akuntansi Keuangan. Jakarta: Salemba Empat.

Irham, Fahmi. 2014. Manajemen Keuangan Perusahaan dan Pasar Modal. Jakarta: Mitra Wacana Media.

Laksitafresti dan Herry Laksito. (2012). "Pengaruh Opini Wajar Tanpa Pengecualian Dengan Paragraf Penjelas dan Opini Wajar Dengan Pengecualian Terhadap Harga Saham dan Volume Perdagangan Saham", eprints.undip.ac.id/3592/1/Jurnal_Astri_Laksitafresti.pdf., diakses tanggal 25 September 2019.

Marcellyne, Fica, Hartini, Titin. 2013. "Pengaruh Earning Per Share (EPS) Terhadap Harga Saham LQ-45 di Bursa Efek Indonesia (BEI)". Jurnal STIE MDP.

Marindah, Afri. 2013. Pengaruh Audit Report Lag, Earnings Per Share, Opini Audit dan Kantor Akuntan Publik Terhadap Harga Saham Pada Perusahaan Manufaktur yang Terdaftar di Bursa Efek Indonesia. Skripsi. Fakultas Ekonomi Universitas Sumatera Utara, Medan.

Martinus. 2017. Analisis Hubungan Opini Auditor, Keterlambatan Penyampaian Laporan Keuangan dan Harga Saham (Studi Empiris Pada Perusahaan Manufaktur yang Terdaftar di Bursa Efek Indonesia Tahun 2013-2015). Skripsi. Fakultas Ekonomi Universitas Sanata Dharma, Yogyakarta.

Nugrahani, Sulih, Ruhiyat, Endang. 2018. Pengaruh Opini Audit Terhadap Harga Saham dengan Ukuran Kantor Akuntan Publik Sebagai Variabel Pemoderasi. Jurnal Akuntansi, Vol.5, No. 1. 
Santika Maya Rindika, Nina Dwi Setyaningsih : Opini Audit, Audit Report Lag, Reporting Delay, Kap, Dan Eps Sebagai Determinan Harga Saham

Oktaviani, N. 2016. Pengaruh Kinerja Lingkuangan Dan Kinerja Social Terhadap Kinerja Keuangan Pada Perusahaan Industri Dasar Dan Kimia Yang Terdaftar Di Bursa Efek Indonesia. Skripsi. STIE Multi Data Palembang, Palembang.

Pardosi, Gerhat. 2012. Analisis Pengaruh Opini Auditor, Audit Report Lag dan Kantor Akuntan Publik Terhadap Harga Saham Pada Perusahaan Manufaktur yang Terdaftar di Bursa Efek Indonesia. Skripsi. Fakultas Ekonomi, Universitas Sumatera Utara, Medan.

Peraturan Otoritas Jasa Keuangan Nomor 29/POJK.04/2016 tentang Laporan Tahunan Emiten atau Perusahaan Publik.

Rimadani, Aulia. 2018. Pengaruh Ukuran KAP, Financial Distress, Opini Audit, Ukuran Perusahaan, dan Audit delay Terhadap Auditor Switching. Skripsi. Fakultas Ekonomi Universitas Islam Indonesia, Yogyakarta.

Rahmawati. 2011. Pengaruh faktor internal dan eksternal perusahaan terhadap audit delay dan timeliness. Skripsi. Fakultas Ekonomi, Universitas Indonesia, Jakarta.

Salehan. 2016. Analisis Pengaruh Opini Audit Wajar Tanpa Pengecualian dan Ketepatan Waktu Penyampaian Laporan Keuangan Terhadap Harga Saham pada Perusahaan Asuransi yang Go Public Di Bursa Efek Indonesia. Thesis. Fakultas Ekonomi Universitas Bhayangkara, Jakarta.

Samsul, Muhamad. 2006. Pasar Modal Dan Manajemen Portofolio. Surabaya: Erlangga.

Sidabutar, Mega Silvia. 2014. Pengaruh Opini Audit, Audit Report Lag, dan Ukuran Kantor Akuntan Publik Terhadap Harga Saham Pada Perusahaan Manufaktur yang Terdaftar di BEI. Skripsi. Fakultas Ekonomi Universitas Negeri Medan, Medan.

Sugiyono. 2017. Metode Penelitian Kuantitatif, Kualitatif, dan RED. Bandung: Alfabeta.

Susila, Agung Budi. 2015. Pengaruh Opini Auditor Terhadap Harga Saham. Skripsi. Fakultas Ekonomi Universitas Sanata Dharma, Yogyakarta. 
Santika Maya Rindika, Nina Dwi Setyaningsih : Opini Audit, Audit Report Lag, Reporting Delay, Kap, Dan Eps Sebagai Determinan Harga Saham

Sutrisna, Kadek, Purnamawati, I Gusti Ayu, Wahyuni, Made Arie. 2017. Pengaruh Keterlambatan Pelaporan Keuangan Terhadap Harga Saham dan Profitabilitas Perusahaan (Studi Kasus Pada Perusahaan Yang Terlambat Menyampaikan Laporan Keuangan di Bursa Efek Indonesia tahun 20142016). E-Journal S1 Ak Universitas Pendidikan Ganesha, Vol.8, No.2.

Yolanda, Suci. 2017. Pengaruh Earnig Per Share Terhadap Harga Saham pada Bank Panin Syariah Indonesia. Skripsi. Fakultas Ekonomi dan Bisnis Islam UIN Raden Fatah, Palembang.

Wiranti, Sri. 2012. Jenis-Jenis Pendapat Auditor (Opini Auditor). Jurnal STIE Semarang, Vol.4, No.2. 